Moore, C. M., Heller, R. H., and Thomas, G. H. (1973). Developmental abnormalities associated with a ring chromosome 6 . fournal of Medical Genetics, 10. (In press.)

Moorhead, P. S., Nowell, P. C., Mellman, W. J., Battips, D. M., and Hungerford, D. A. (1960). Chromosome preparations of leukocytes cultured from human peripheral blood. Experimental Cell Research, 20, 613-616.

Riccardi, V. M., Atkins, L., and Holmes, L. B. (1970). Absent patellae, mild mental retardation, skeletal and genitourinary anomalies, and $\mathrm{C}$ group autosomal mosaicism. Fournal of Pediatrics, 77, 664-672.

Stalder, G. R., Buhler, E. M., and Weber, J. R. (1963). Possible trisomy in chromosome group 6-12. Lancet, $1,1379$.

Stolte, L., Evers, J., and Blankenborg, G. (1964). Possible trisomy in chromosome group 6-12 in a normal woman Lancet, 2., $480-481$.

Taylor, H. A., Thomas, G. H., Miller, C. S., Kelley, T. E., and Siggers, D. (1973). Mucolipidosis 111 (pseudo-Hurler polydystrophy): cytological and ultrastructural observations of cultured fibroblast cells. Clinical Genetics. (In press.)

Wolf, U. and Reinwein, H. (1965). Chromosomenmosaik Ctrisomie/normal. Humangenetik, 1, 686-687.

\section{A Case of Trisomy 9}

Summary. The first patient with trisomy 9, an infant who survived 28 days, is reported. Clinical findings included microcephaly, low-set malformed ears, small palpebral fissures, enophthalmos, bulbous nose, micrognathia, low hairline, congenital heart disease, skeletal abnormalities, small penis, hypoplastic scrotum, and a Dandy-Walker like deformity of the fourth ventricle.

Although there are numerous reports of an extra chromosome in the $\mathrm{C}$ group, identification of the additional chromosome as a No. 9 has not been demonstrated. The purpose of this report is to document the first example of trisomy 9.

\section{Case Report}

A male infant was admitted to the Boston Floating Hospital for Infants and Children at the age of 2 days because of multiple congenital anomalies. He was the product of a 40 -week gestation of a normal 24-year-old gravida 2, para 2, female and a 25 -year-old male. Birth weight was $3218 \mathrm{~g}$. During the first and second trimesters the mother had severe nausea with vomiting as well as vaginal spotting, bronchitis, and sinusitis. There was no known exposure to irradiation or infectious diseases. During the pregnancy the mother received the following medications: Erythromycin, Percogesic

Received 17 January 1973 (phenyltoloxamine and acetaminophen), Compazine (prochlorperazine), Bendectine (dicyclomine hydrochloride, dexylamine succinate, and pyridoxine hydro-
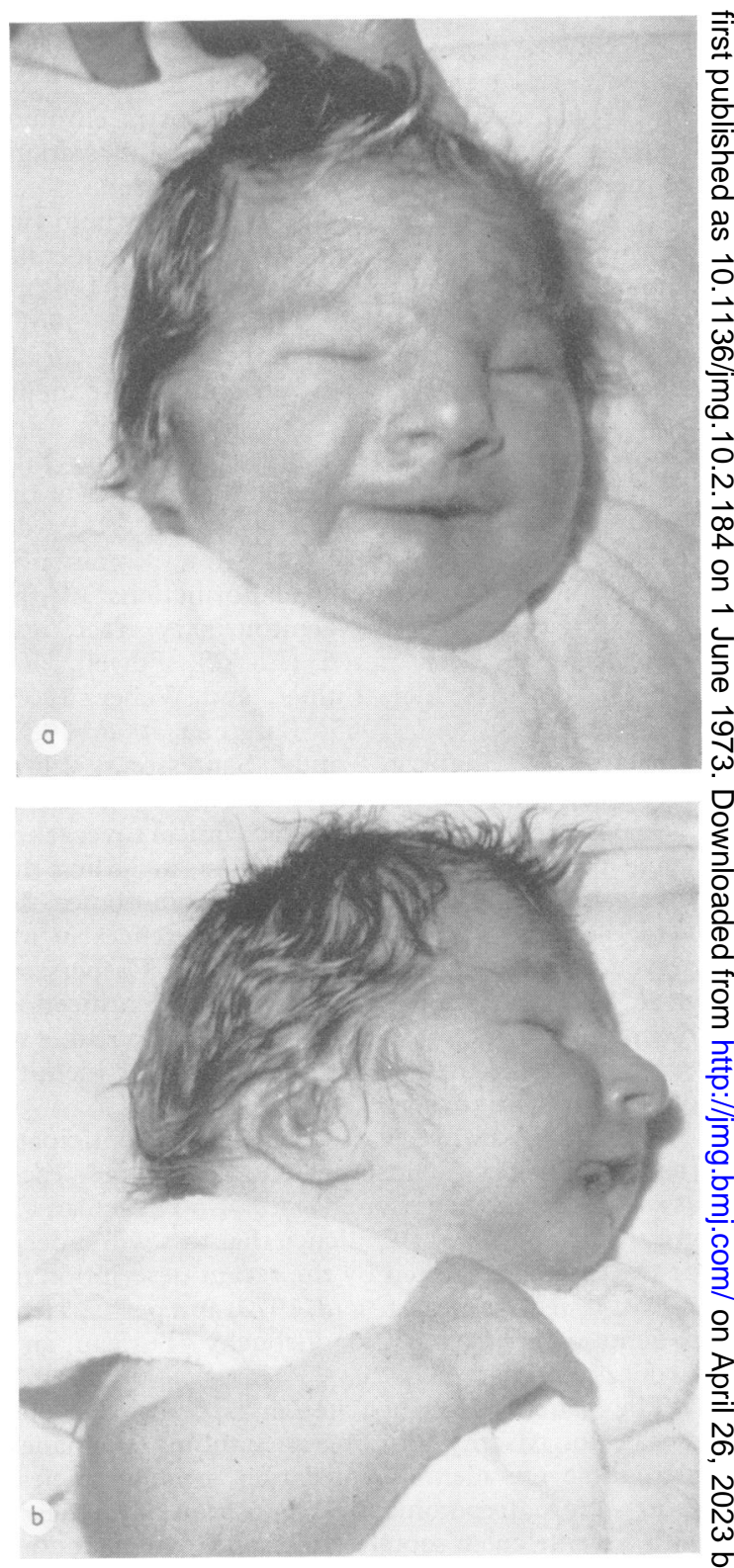

FIG. 1a and 1b. Front and side views of the face showing small palpebral fissures, bulbous nose, low-set and abnormally shaped ears, and micrognathia. 
chloride), and Donnatal (hyoscyamine sulphate, atropine sulphate, scopolamine hydrobromide, and phenobarbital), and two intramuscular injections of Imferon.

The father has juvenile diabetes mellitus and had a myocardial infarction. The paternal grandmother and a paternal uncle also had diabetes. A 3-year-old female sib is normal. There was no family history of birth defects or mental retardation.

Physical examination on admission showed a weight of $3180 \mathrm{~g}$, a head circumference of $32.5 \mathrm{~cm}$, and a height of $50.8 \mathrm{~cm}$. His face was distinctive with small palpebral fissures, enophthalmos, bulbous nose, marked micrognathia, and low-set malformed ears (Fig. 1). The overall facial appearance was similar to that seen in patients with trisomy 13. The head was small, and the neck was somewhat webbed with a low hairline. A grade III systolic murmur was heard best at the left sternal border. The liver and spleen were not enlarged. The penis was very small, and the scrotum was hypoplastic (Fig. 2). The nails were hyperconvex and the thumbs were retroflexed. There was inability to flex the fingers at the interphalangeal joints, and the fingers were tapered. On the left there was only one toe present, and on the right the big toe was normal, but the remaining toes were very short (Fig. 2). There was limitation of motion of the hips bilaterally. He had a fair suck, a low pitched cry, and a decreased Moro reflex.

The white-cell count and haematocrit were normal, as were the serum electrolytes, immunoelectrophoresis and urinalysis. Radiology of the chest and skull and an intravenous pyelogram were normal. $X$-ray films of the left lower limb showed lack of development of the tibia and absence of the left fibula. There was a single left toe represented by a metatarsal and two phalangeal bones. The tarsal and calcaneal bones were missing bilaterally. On the right the distal phalangeal bones of the second, third, fourth, and fifth toes were missing. There was bilateral dislocation of the head of the radius.

The baby gained weight poorly. An omphalitis developed which responded to antibiotic treatment. On the 26th day in hospital he developed laboured respirations and bradycardia and expired shortly thereafter.

Necropsy showed the skeletal and facial abnormalities which had previously been noted. Cardiac anomalies included a double outlet right ventricle with a patent foramen ovale, ventricular septal defect, hypertrophy of both ventricles, dilated pulmonary artery, and a patent ductus arteriosus. The left superior vena cava drained into a dilated coronary sinus in the right atrium and the aorta arose from the right ventricle. A preductal coarctation of the aorta and endocardial fibroelastosis of the right ventricle were also noted. There were also focal bilateral acute bronchopneumonia, a Dandy-Walker like dilatation of the fourth ventricle with nonfusion of the cerebellum in the midline, and fatty changes and focal infiltrates of mononuclear cells of the liver with bile stasis.

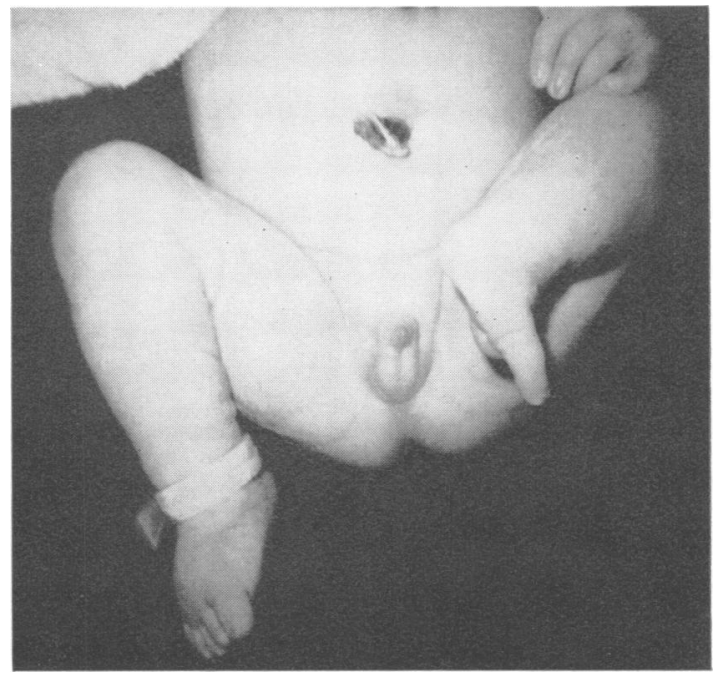

Fig. 2. Deformed left foot with only one toe, and small penis and scrotum.

\section{Cytogenetic Studies}

Routine chromosome preparations from cultured leucocytes of the propositus showed 47 chromosomes with an extra member of the $\mathrm{C}$ group in 63 consecutive cells examined. Quinacrine mustard fluorescence staining (Caspersson, Lomakka, and Zech, 1971) showed the extra chromosome to be a No. 9 (Fig. 3). Trisomy for No. 9 was also demonstrated by a modification of the trypsin banding technique of Seabright (1971). The remainder of the karyotype appeared normal. Cultured leucocytes of both parents showed normal karyotypes with routine preparations and with quinacrine mustard fluorescence staining.

\section{Discussion}

Of the reported examples of $\mathrm{C}$ trisomy the case of Juberg, Gilbert, and Salisbury (1970) most closely resembles the patient under discussion. In common with theirs, our patient had a flattened nasal bridge, epicanthal folds, micrognathia, and low-set ears. However, the patient of Juberg and his coworkers also showed a number of features not found in the present case. These findings included a midline cleft palate, hyperextensible joints, dislocated hips, and bilateral cystic disease of the kidneys and ovaries. Specific identification of the extra Cgroup chromosome was not made.

Trisomy for the short arm of chromosome No. 9 


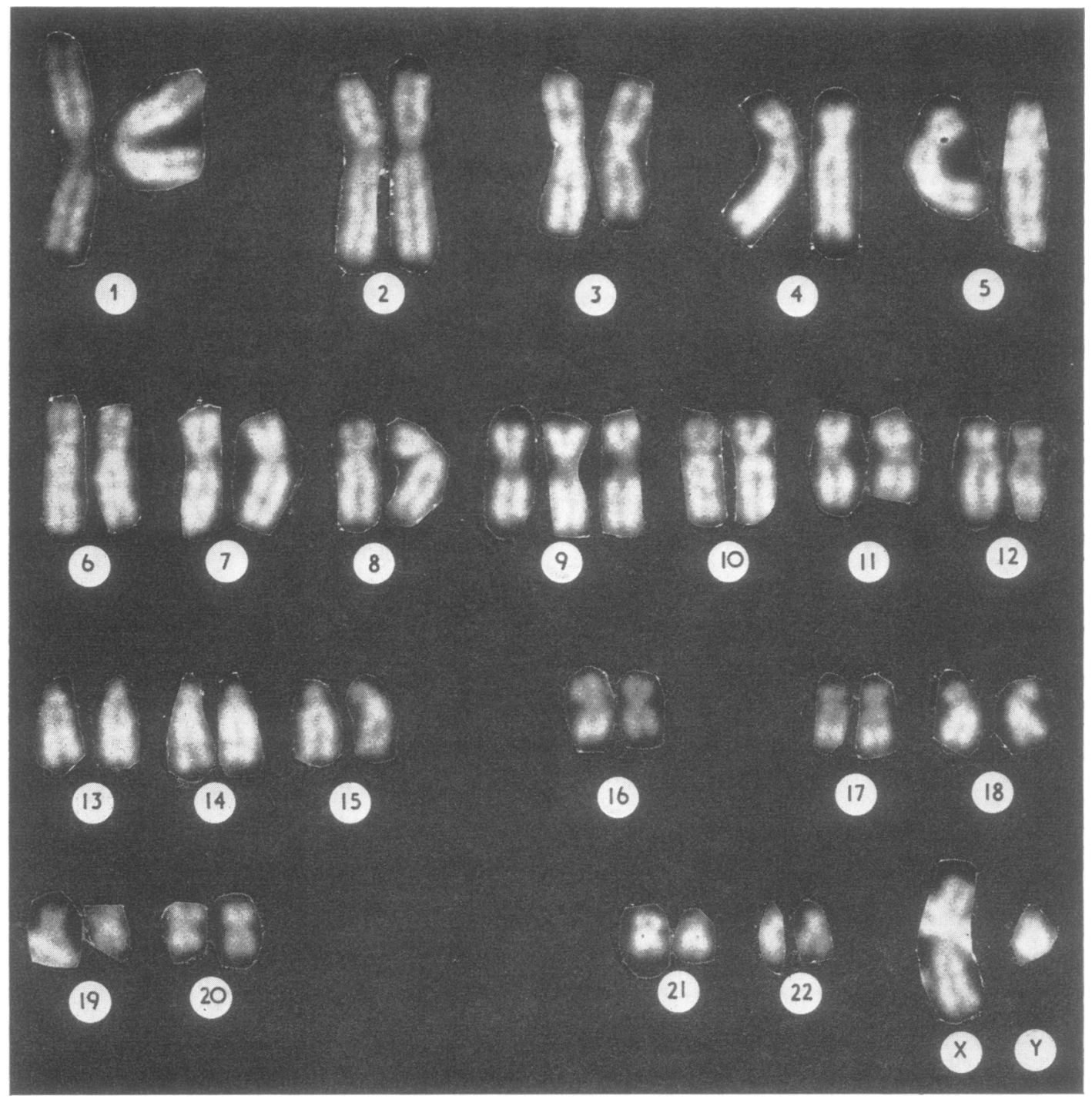

FIG. 3. Karyotype of patient prepared after quinacrine mustard fluorescence staining.

has been reported in four cases by Rethoré et al (1970) and one by Hoehn, Engel, and Reinwein (1971). The clinical manifestations included severe mental retardation, enophthalmos, mild hypertelorism, globulous nose, abnormal antihelix, and hypoplasia of the second and third phalanges. Although some of the above features were present in the case under discussion, the similarity was not marked. Nor was our patient similar to the one described by Cantu, Buentello, and Armendares (1971) who had a partial trisomy for the short arm of a group $\mathrm{C}$ chromosome or the four patients with trisomy 8 described by Caspersson et al (1972). Many of the other reported cases of $\mathrm{C}$ trisomy were mosaics and clinically did not resemble our patient. Of particular interest was the resemblance between the facies of the propositus and patients with trisomy 13 (small palpebral fissures, enophthalmos, bulbous nose, micrognathia, abnormal ears, hyperconvex nails, and retroflexed thumbs). 
We wish to thank Miss Ida Leone and Mrs Charlotte Kayavas for technical assistance. The quinacrine mustard was supplied by $\mathrm{S}$. Archer PhD of SterlingWinthrop Research Institute, Rensselaer, New York. This work was partially supported by The Children's Bureau (Federal Grant MGH MR) and The National Foundation.

\section{Murray Feingold and Leonard Atkins}

Center for Genetic Counseling, New England Medical Center (Boston Floating Hospital for Infants and Children), Tufts University School of Medicine and the Fames Homer Wright Pathology Laboratories of the Massachusetts General Hospital, Boston, Massachusetts, USA

\section{REFERENCES}

Cantu, J.-M., Buentello, L., and Armendares, S. (1971). Trisomie $\mathrm{Cp}$ : un nouveau syndrome. Annales de Génétique, 14, 177-186. Caspersson, T., Lindsten, J., Zech, L., Buckton, K. E., and Price, W. H. (1972). Four patients with trisomy 8 identified by the fluorescence and Giemsa banding techniques. Fournal of Medical Genetics, 9, 1-7.

Caspersson, T., Lomakka, G., and Zech, L. (1971). The 24 fluorescence patterns of the human metaphase chromosomes-distinguishing characters and variability. Hereditas, Genetisk Arkiv, 67, 89-102.

Hoehn, H., Engel, W., and Reinwein, H. (1971). Presumed trisomy for the short arm of chromosome no. 9 not due to inherited translocation. Humangenetik, 12, 175-181.

Juberg, R. C., Gilbert, E. F., and Salisbury, R. S. (1970). Trisomy $\mathrm{C}$ in an infant with polycystic kidneys and other malformations. Fournal of Pediatrics, 76, 598-603.

Rethoré, M.-O., Larget-Piet, L., Abonyi, D., Boeswillwald, M., Berger, R., Carpentier, S., Cruveiller, J., Dutrillaux, B., Lafourcade, J., Penneau, M., and Lejeune, J. (1970). Sur quatre cas de trisomie pour le bras court du chromosome 9 . Individualisation d'une nouvelle entité morbide. Annales de Génétique, 13, 217-232.

Seabright, M. A. (1971). Rapid banding technique for human chromosomes. (Letter.) Lancet, 2, 971-972.

\section{Partial Trisomy of the Long Arm of Chromosome No. $7^{*}$}

Summary. A case report on an infant with trisomy of the distal third of the long arm of chromosome No. 7 is presented.

The report of a child with $46, \mathrm{XY}, 14 \mathrm{q}+$ karyotype is presented. The extra segment on the long arm of chromosome No. 14 was identified as the distal one third of the long arm of chromosome

\footnotetext{
Received 6 February 1973.

* This work was supported in part by Department of Health, Education and Welfare, Maternal and Child Health Service project 422 .
}

No. 7. This case thus has a partial trisomy of the long arm of chromosome No. 7, a condition which has not been described previously.

\section{Case Report}

The propositus, a 5-month-old male, with a history of recurrent pneumonias and failure to thrive, was born to a 39-year-old, gravida 4 para 4, mother and a 44 -year-old father. Both parents had been married before, and the propositus is the only product of the present marriage. Family history was negative for abortions, stillbirths, or congenital malformations. Gestation was full term, with a breech presentation, and polyhydramnios. A Caesarean section was performed because of an obstetric problem in a previous pregnancy. Birth weight was $2012 \mathrm{~g}$. There were early respiratory and feeding difficulties. Recurrent pneumonias over the first four months of life necessitated almost continuous hospitalization.

The propositus was first seen at the Children's Hospital of Los Angeles at the age of $4 \frac{1}{2}$ months. He weighed $3450 \mathrm{~g}$. His height was $51.5 \mathrm{~cm}$ and head circumference was $41 \mathrm{~cm}$. He had an asymmetric head, with prominent occiput, more so on the right side. The anterior fontanelle was widely patent $(8 \times 10 \mathrm{~cm})$. The

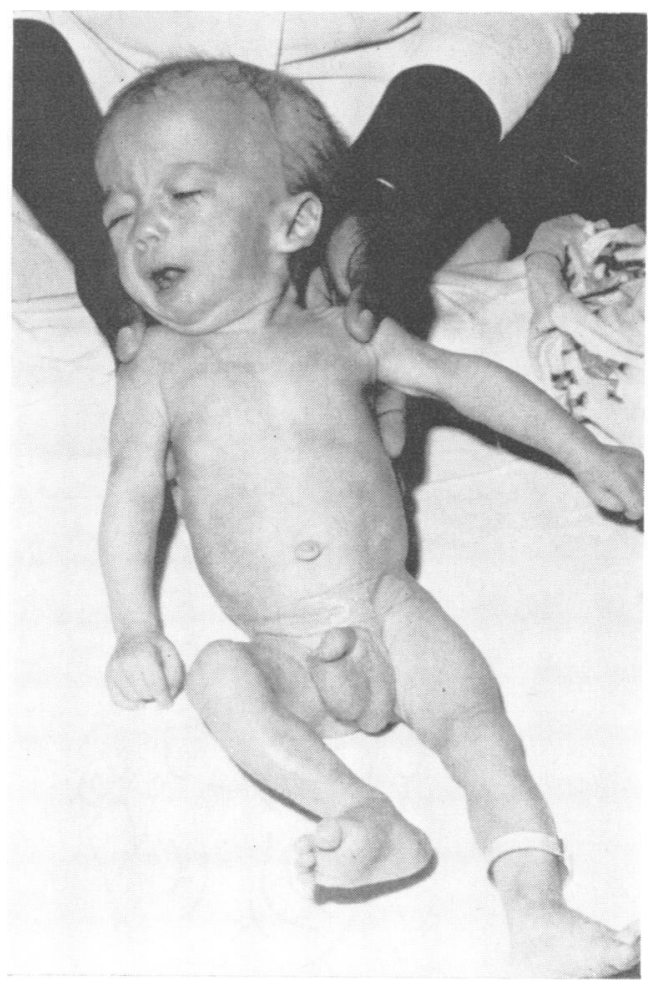

FIG. 1. The propositus. 